\title{
Therapeutic potential of caffeic acid phenethyl ester and its anti-inflammatory and immunomodulatory effects (Review)
}

\author{
FERAH ARMUTCU $^{1}$, SUMEYYA AKYOL ${ }^{2}$, SEYFETTIN USTUNSOY $^{3}$ and FATIME FILIZ TURAN ${ }^{3}$ \\ ${ }^{1}$ Department of Biochemistry, Cerrahpasa Medical Faculty, Istanbul University, Istanbul 34098; \\ ${ }^{2}$ Department of Medical Biology, Medical Faculty, Turgut Ozal University, Ankara 06010; \\ ${ }^{3}$ Department of Biochemistry, Medical Faculty, Fatih University, Istanbul 34500, Turkey
}

Received July 4, 2014; Accepted March 3, 2015

DOI: $10.3892 /$ etm.2015.2346

\begin{abstract}
Caffeic acid phenethyl ester (CAPE), a naturally occurring compound isolated from propolis extract, has been reported to have a number of biological and pharmacological properties, exerting antioxidant, anti-inflammatory, anticarcinogenic, antibacterial and immunomodulatory effects. Recent in vivo and in vitro study findings have provided novel insights into the molecular mechanisms involved in the anti-inflammatory and immunomodulatory activities of this natural compound. CAPE has been reported to have anti-inflammatory properties involving the inhibition of certain enzyme activities, such as xanthine oxidase, cyclooxygenase and nuclear factor- $\kappa \mathrm{B}$ $(\mathrm{NF}-\kappa \mathrm{B})$ activation. Since inflammation and immune mechanisms play a crucial role in the onset of several inflammatory diseases, the inhibition of $\mathrm{NF}-\kappa \mathrm{B}$ represents a rationale for the development of novel and safe anti-inflammatory agents. The primary goal of the present review is to highlight the anti-inflammatory and immunomodulatory activities of CAPE, and critically evaluate its potential therapeutic effects.
\end{abstract}

Correspondence to: Professor Ferah Armutcu, Department of Biochemistry, Cerrahpasa Medical Faculty, Istanbul University, 1 Kocamustafapasa Street, Istanbul 34098, Turkey

E-mail: drferah@gmail.com

Abbreviations: CAPE, caffeic acid phenethyl ester; CD68, cluster of differentiation 68; COX-2, cyclooxygenase-2; EAE, experimental autoimmune encephalomyelitis; IFN- $\gamma$, interferon- $\gamma$; IкB- $\alpha, \kappa$ B inhibitor- $\alpha$; IKK, IкB-kinase; IL-1, interleukin-1; iNOS, inducible nitric oxide synthase; LPS, lipopolysaccharide; MAPK, mitogen-activated protein kinase; MCP-1, monocyte chemoattractant protein-1; MDA, malondialdehyde; MPO, myeloperoxidase; MoDC, monocyte-derived dendritic cell; MS, multiple sclerosis; NF- $\kappa \mathrm{B}$, nuclear factor $\kappa \mathrm{B}$; NO, nitric oxide; Nrf2, nuclear-factor-E2-related factor 2; PAF, platelet-activating factor; PLD1, phospholipase D1; ROS, reactive oxygen species; TNF- $\alpha$, tumor necrosis factor- $\alpha$; XO, xanthine oxidase

Key words: caffeic acid phenethyl ester, anti-inflammatory activity, immunomodulatory effect

\section{Contents}

1. Introduction

2. Overview to the inflammatory response

3. Proinflammatory cytokines and signaling pathways

4. Anti-inflammatory effects of CAPE

5. Immunomodulatory effects of CAPE

6. Conclusion

\section{Introduction}

Caffeic acid phenethyl ester (CAPE) is an important active component of honeybee propolis extract and has been used in traditional medicine for a number of years. CAPE is a polyphenol that contains hydroxyl groups within a catechol ring, the molecular formula of CAPE is $\mathrm{C}_{17} \mathrm{H}_{16} \mathrm{O}_{4}(1,2)$ (Fig. 1). It has been shown that this active component of propolis possesses anti-inflammatory, immunomodulatory, antineoplastic, antioxidant and wound-healing properties (1-4). Inflammation is induced by the release of chemical mediators from damaged tissue and migratory cells. Mediators identified in the inflammatory process include biogenic amines, metabolites of arachidonic acid (eicosanoids), platelet aggregation factors, cytokines [interleukins (ILs) and tumor necrosis factor- $\alpha$ (TNF- $\alpha$ )] and free oxygen radicals. These substances are produced by inflammatory cells, such as polymorphonuclear leukocytes (neutrophils, eosinophils and basophils), endothelial cells, mast cells, macrophages, monocytes and lymphocytes $(5,6)$. CAPE inhibits cytokine and chemokine production, the proliferation of $\mathrm{T}$ cells and lymphokine production, and thus suppresses the inflammatory process. Specifically, CAPE is a potent and a specific inhibitor of nuclear factor- $\kappa \mathrm{B}(\mathrm{NF}-\kappa \mathrm{B})$ activation, and this may provide the molecular basis for its multiple anti-inflammatory and immunomodulatory activities $(2,7)$. The aim of this review is to highlight the anti-inflammatory and immunomodulatory activities of CAPE, focusing on the mechanisms of action (already identified) underlying this activity.

\section{Overview to the inflammatory response}

Inflammation is an immunological response to pathogens and damage that is initiated to protect the body, and contributes 
to physiological and pathological processes, such as wound healing and infection at the compromised site. The process is accompanied by adhesion, migration and chemotaxis of leukocytes to the inflammatory environment (6). In response to tissue injury, a multifactorial network of chemical signals initiates and maintains a host response designed to 'heal' the afflicted tissue. The first effectors recruited in the acute inflammatory response are neutrophils. These are followed by monocytes, which undergo differentiation in the tissue into macrophages and migrate to the site of tissue injury under the guidance of chemotactic factors $(5,8)$. The activated leukocytes provide proinflammatory cytokines, reactive oxygen species (ROS) and matrix metalloproteinases to remove the invading pathogen (9). The pathogens and damaged tissue are then phagocytosed, and the inflammatory process is eventually terminated when lipoxins start to overrule the proinflammatory signals (10). In general, IL-1 and TNF target the endothelium and initiate the inflammatory mediator cascade following exposure to certain stimuli, including infection, trauma, ischemia, immune-activated $\mathrm{T}$ cells or toxins. The inflammatory cascade can be summarized as follows: i) Activation of inflammatory cytokine-secreting cells, and increases in the levels of proinflammatory cytokines, such as IL-1, TNF- $\alpha$ and interferon- $\gamma$ (IFN- $\gamma$ ); ii) activation/synthesis of phospholipase A2, cyclooxygenase-2 (COX-2) and inducible nitric oxide synthase (iNOS); increased endothelial adhesion molecules and synthesis of chemokines; iii) increased platelet-activating factor (PAF), leukotriene, prostanoid (prostaglandin E2) and NO levels, neutrophil endothelial adhesion, and the migration and activation of neutrophils; and iv) inflammation, tissue destruction and loss of function (10-12).

\section{Proinflammatory cytokines and signaling pathways}

Cytokines are polypeptide regulators of host responses to infection, immune responses, inflammation and trauma. Cytokine secretion by immune cells has a pivotal role in directing the course of an inflammatory response. Cellular cytokine production is regulated at transcriptional and translational levels and via cell signaling (11). Certain cytokines act to enhance the effects of the disease (proinflammatory), whereas others are involved in reducing inflammation and promoting healing (anti-inflammatory). Methods to block potentially harmful cytokines, particularly during an overwhelming infection, have been an area of particular interest. Administration of the proinflammatory cytokines IL-1 and TNF- $\alpha$ to humans can lead to fever, inflammation, tissue destruction and, in certain cases, shock and mortality $(9,12)$. TNF- $\alpha$ is a 'master regulator' among cytokines and is responsible for mediating the inflammatory responses and innate immunity. The major pathways activated by TNF- $\alpha$ include caspases, NF- $\kappa \mathrm{B}$ and mitogen-activated protein kinases (MAPKs). Crosstalk between these signaling pathways plays a role in determining the physiological outcome of the responses to TNF- $\alpha$ (13). The network response is further complicated by the phases associated with TNF- $\alpha$ signaling: In the early phase, TNF- $\alpha$ signaling induces the expression of inflammatory cytokines; this then initiates a secondary cytokine-mediated cellular response that contributes to the biological activity of TNF- $\alpha$ (14).

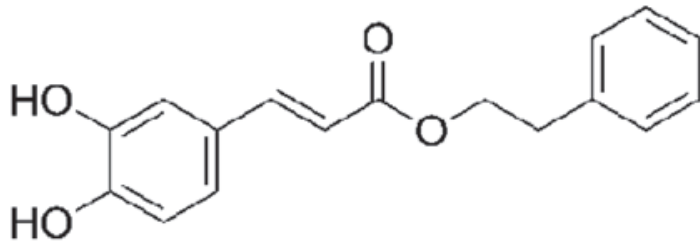

Figure 1. Chemical structure of caffeic acid phenethyl ester.

The transcription factor $\mathrm{NF}-\kappa \mathrm{B}$ plays a central role in regulating inflammatory, immune and anti-apoptotic responses. It is composed of homodimers and heterodimers of the Rel family of proteins, including p65/RelA, RelB, c-Rel, p50/p105 and $\mathrm{p} 52 / \mathrm{p} 100(15,16)$. The activation of inactive $\mathrm{NF}-\kappa \mathrm{B}$ proteins existing in the cytoplasm is induced by numerous factors, including inflammatory cytokines (IL-1 and TNF- $\alpha$ ), bacterial products and protein synthesis inhibitors (17); therefore, agents that can downregulate the activation of $\mathrm{NF}-\kappa \mathrm{B}$ have potential for therapeutic interventions, whereas the activation of $N F-\kappa B$ promotes inflammation in animals. The binding of TNF- $\alpha$ to cell surface receptors engages multiple signal transduction pathways, including three groups of MAPKs: Extracellular-signal-regulated kinases, c-Jun N-terminal kinases and p38 MAPKs. These MAPK signaling pathways induce a secondary response by increasing the expression of several inflammatory cytokines that contribute to the biological activity of TNF- $\alpha$. MAPKs, therefore, function both upstream and downstream of signaling by TNF- $\alpha$ receptors $(13,18)$. In almost all cell types, the exposure of the cells to TNF- $\alpha$ induces the activation of NF- $\kappa \mathrm{B}$ and leads to the expression of a range of genes associated with inflammation. $\mathrm{NF}-\kappa \mathrm{B}$ is a protein complex that controls the transcription of DNA and is a central regulator of cellular stress in all cell types in humans. $\mathrm{NF}-\kappa \mathrm{B}$ plays a key role in regulating the immune response to infection and in acute and chronic inflammation. The activation of $\mathrm{NF}-\kappa \mathrm{B}$ in rats can induce the expression of IL-1 $\beta$, which increases the expression of proinflammatory molecules $(17,19)$.

\section{Anti-inflammatory effects of CAPE}

The transcription factor $\mathrm{NF}-\kappa \mathrm{B}$ has a pivotal role in a variety of physiological processes throughout the body, including immune responses, cell proliferation and inflammation. $\mathrm{NF}-\kappa \mathrm{B}$ elicits its effects by promoting the transcription of a range of cytokines, enzymes, chemokines and antiapoptotic and cell growth factors (20). Several in vitro and in vivo studies have described diverse biological activities of CAPE (at micromolar concentrations), such as a specific inhibition of NF- $\kappa \mathrm{B}$ and a suppression of the lipoxygenase pathway of arachidonic acid metabolism during inflammation (2-4). It has also been shown that CAPE acts to suppress the NF- $\kappa \mathrm{B}$ activation induced by ROS-generating agents in human histiocytic and coronary artery endothelial cells (2). It is believed that, rather than preventing the degradation of $\kappa \mathrm{B}$ inhibitor- $\alpha$ (I $\kappa \mathrm{B}-\alpha$ ), CAPE suppresses $\mathrm{NF}-\kappa \mathrm{B}$ activation by inhibiting the interaction between $\mathrm{NF}-\kappa \mathrm{B}$ proteins and DNA (21) (Fig. 2). Ilhan et al (22) suggested that the anti-inflammatory effect of CAPE is most likely due to the inhibition of ROS 


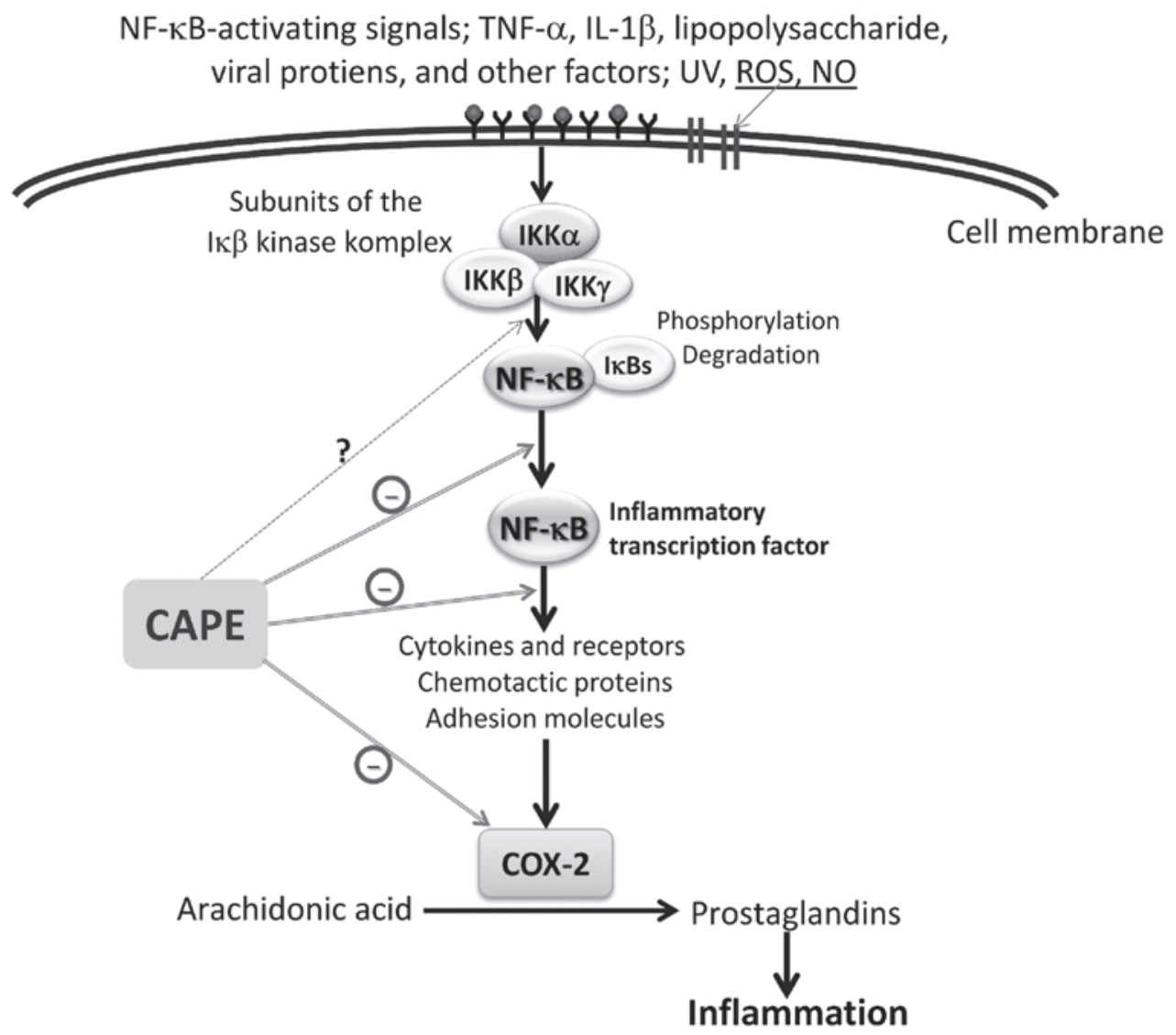

Figure 2. Schematic presentation of the anti-inflammatory effects of CAPE in the inhibition of inflammation. COX-2, cyclooxygenase-2; IкB- $\alpha, \kappa B$ inhibitor- $\alpha$; IKK, IкB-kinase; IL-1 $\beta$, interleukin-1 $\beta$; NF- $\mathrm{BB}$, nuclear factor $\kappa \mathrm{B}$; NO, nitric oxide; ROS, reactive oxygen species; TNF- $\alpha$, tumor necrosis factor- $\alpha$; UV, ultraviolet.

production at the transcriptional level, through the suppression of $\mathrm{NF}-\kappa \mathrm{B}$ activation, and the direct inhibition of the catalytic activity of iNOS. Toyoda et al (23) reported that CAPE treatment inhibited Helicobacter pylori-induced $N F-\kappa B$ activation via the suppression of I $\kappa \mathrm{B}-\alpha$ degradation and the phosphorylation of $\mathrm{p} 65$ in a gastric cancer cell line. Furthermore, the results clearly demonstrated that the mRNA expression levels of inflammatory factors known to be induced by $\mathrm{NF}-\kappa \mathrm{B}$ transcriptional activation, such as TNF- $\alpha$, IFN- $\gamma$, IL-2, IL-6, iNOS and KC, an IL-8 homologue chemokine, were all significantly decreased by CAPE treatment in the pyloric mucosa of $H$. pylori-infected Mongolian gerbils $(23,24)$. Colonization of gastric epithelial cells with $H$. pylori induces $\mathrm{NF}-\kappa \mathrm{B}$ and results in the increased production of the proinflammatory cytokines TNF- $\alpha$, IL-1, IL- 6 and IL-8, all of which are regulated by NF- $\kappa \mathrm{B}(25,26)$. It has also been demonstrated that local administration of CAPE leads to increased levels of leukocyte apoptosis and marked reductions in the concentrations of leukocytes, neutrophils and monocytes in the inflammatory site exudate. Furthermore, CAPE decreases the levels of cytosolic I $\kappa \mathrm{B}-\alpha$ and increases the nuclear translocation of p65 (27).

CAPE possesses strong antioxidant, anti-inflammatory and healing properties, and its effects on the wound healing have been attributed to the inhibition of $\mathrm{NF}-\kappa \mathrm{B}(28,29)$. Consistent with these two cited studies, Santos et al (30) reported that treatment with CAPE enhanced wound healing, particularly wound healing following burns; decreased inflammatory parameters and oxidative damage; and inhibited the activity of cyclooxygenase and lipooxygenase. Under most inflammatory conditions, such as in thermal injury, NO production is enhanced. In addition to performing histological and biochemical analyses, Santos et al (30) evaluated the anti-cluster of differentiation 68 (CD68) and NO levels, as well as myeloperoxidase (MPO) activity. CAPE exhibited an anti-inflammatory action on rat burn healing by reducing MPO activity, NO levels and the number of CD68-positive cells (30). Khan et al (31) demonstrated that CAPE reduced neurovascular inflammation and protected the rat brain following transient focal cerebral ischemia by downregulating $\mathrm{NF}-\kappa \mathrm{B}$ and certain mediators, such as cytokines and iNOS (31).

CAPE classically exerts anti-inflammatory effects by reducing prostaglandin and leukotriene synthesis. Furthermore, it has been suggested that the anti-inflammatory action exhibited by CAPE is a result of the inhibition of arachidonic acid release from the cell membrane. As a consequence of this inhibition, the activity of COX-1 and -2 and the activation of the COX-2 gene expression are suppressed $(32,33)$. Recently, the protective effect of CAPE on a model of eccentric exercise-induced muscle injury was investigated (34). The study results showed that inflammatory skeletal muscle injury enhanced the expression of COX-2 and iNOS, as well as the production of IL-1 $\beta$ and monocyte chemoattractant protein-1 (MCP-1). It was proposed that these pathological changes in the rats were suppressed by 
CAPE, which blocked the NF- $\kappa \mathrm{B}-$ dependent activation of the inflammatory response (34). In another in vitro study, CAPE significantly suppressed the levels of lipopolysaccharide (LPS)-induced IL-1 $\beta$, TNF- $\alpha$ and MCP-1 from a macrophage cell line, RAW264.7 (35). Furthermore, in a recent study of RAW264.7 murine macrophage in vivo models, CAPE reduced the production of cytotoxic molecules, such as NO and peroxynitrite, and thus suppressed the inflammatory responses that could have resulted in cell damage and, potentially, cell death. According to the study results, RAW264.7 cells under LPS/IFN $\gamma$ stimulation exhibited significantly improved viability following treatment with CAPE, which also inhibited NO production in a similar manner to an iNOS inhibitor. This indicated that CAPE exhibits therapeutic potential in a variety of inflammatory disorders (36).

$\mathrm{NF}-\kappa \mathrm{B}$ signaling additionally has central roles in precancerous chronic inflammation and cancer-induced inflammation (37). CAPE acts to downregulate inflammation by blocking NF- $\kappa \mathrm{B}$, and affects a variety of mediators, including adhesion molecules, cytokines and iNOS. CAPE is a well-documented inhibitor of $\mathrm{NF}-\kappa \mathrm{B}$, which may be an action mechanism for the CAPE-mediated anti-inflammatory and anticancer effects $(4,38)$. Although CAPE has been described to conduct its anti-inflammatory activities by modulating different inflammatory pathways, including inhibition of the transcription factors $\mathrm{NF}-\kappa \mathrm{B}$ and signal transducer and activator of transcription 3 (acute-phase response factor), the compound has already been evaluated for antitumor efficacy in numerous in vitro and in vivo studies $(39,40)$. Coimbra et al (41), for example, investigated the antitumor efficacy of liposomal formulations of CAPE that are known to interfere with inflammatory signaling pathways and have been described to exert antitumor effects. Furthermore, CAPE has been demonstrated to be selectively cytotoxic to cancer cells (42-44). Previous studies found that CAPE could rapidly enter HL-60 cells and induce glutathione depletion (42), mitochondrial dysfunction and caspase-3 activation (43). In a study by Park et al (45) it was observed that CAPE suppressed the expression of phospholipase D1 (PLD1) at the transcriptional level by preventing the binding of $N F-\kappa B$ to the PLD1 promoter. This suggested that the CAPE-induced suppression of matrix metalloproteinase- 2 and invasion was mediated by the downregulation of PLD1 by CAPE in glioma cells. Several proposed molecular anti-inflammatory mechanisms of CAPE have been suggested by in vivo and in vitro studies. Table I $(22,23,30,34,35,46-50)$ summarizes the anti-inflammatory effects of CAPE.

\section{Immunomodulatory effects of CAPE}

Although the mechanisms underling CAPE-induced NF- $\mathrm{B}$ inhibition have yet to be fully elucidated, the anti-inflammatory and immunomodulatory effects of the compound have been demonstrated in human and experimental models. Immunological studies have indicated that CAPE strongly inhibits mitogen-induced T-cell proliferation, lymphokine production and $\mathrm{NF}-\kappa \mathrm{B}$ activation $(22,27,50)$. Furthermore, CAPE has been shown to regulate the nuclear binding of the $N F-\kappa B$ subunit p65/RelA, attenuate the expression of cytosolic I $\mathrm{K}$ - $\alpha$ and suppress the dephosphorylation and
T-cell transcriptional activity of nuclear factor of activated $\mathrm{T}$ cells (51). It has additionally been demonstrated that CAPE can inhibit eicosanoid synthesis, and $\mathrm{NF}-\kappa \mathrm{B}$ activation may be a causative factor for the increased expression of numerous inflammatory genes in asthma $(52,53)$. NF- $\kappa \mathrm{B}$ is expressed in the majority of cell types, and is known to play a central role in immune and inflammatory responses, including asthma. In a study by Jung et al (54) CAPE was found to be capable of downregulating NF- $\mathrm{NB}$ activity and reducing the levels of eosinophil peroxidase, indicating that CAPE could be considered as an adjuvant therapy for patients with bronchial asthma. Consistent with these observations, Choi et al (55) demonstrated the importance of $\mathrm{NF}-\kappa \mathrm{B}$ in the pathogenesis of asthma in mice. In addition, Park et al (56) showed that there was a significant decrease in the cellularity of the spleen and thymus and the thymus weight of mice treated with CAPE at a dose of $20 \mathrm{mg} / \mathrm{kg}$. These results suggested that the treatment of CAPE directly or indirectly caused the immune cells to decrease in cell number, particularly T cells. A different study strongly indicated that the anti-allergy effect of CAPE was a result of the suppression of IgE levels occurring due to the inhibition of NF- $\kappa \mathrm{B}$ activation and PAF release (57). Furthermore, it has been reported that CAPE suppresses the contraction of guinea-pig trachea induced by histamine and adenosine. CAPE may therefore be an effective therapeutic agent for allergic diseases (58).

\section{Conclusion}

In conclusion, CAPE, a compound recognized as the active component of propolis extract, has anti-inflammatory, antioxidant and immunomodulatory properties. Additionally, CAPE inhibits the transcriptional activity of the COX-2 gene in epithelial cells, iNOS gene expression and NO production in macrophage cell lines, and suppresses eicosanoid synthesis and the release of arachidonic acid from cell membranes. In accordance with the above effects, it has been demonstrated that CAPE is a potent and specific inhibitor of NF- $\kappa \mathrm{B}$, lipid peroxidation and lipoxygenase. $\mathrm{NF}-\kappa \mathrm{B}$ therefore represents a potential target for novel therapeutic agents developed to block the inflammatory response in cases where this process has become chronic or dysregulated. In addition, abnormalities in the $N F-\kappa B$ pathway are frequently observed in a variety of types of human cancer. NF- $\mathrm{NB}$ pathway activation is associated with the pathogenesis of chronic inflammatory diseases, including asthma, atherosclerosis, rheumatoid arthritis, inflammatory bowel disease and cancer (59). Furthermore, CAPE demonstrates potential health benefits for the prevention of obesity and associated metabolic disorders and is a potential drug candidate for ischemic stroke treatment due to its inhibition of oxidative stress and inflammation, examples that illustrate how clinically relevant it can be across a wide therapeutic window $(49,59)$. The findings described in this review provide novel insights into the molecular mechanisms underlying the immunomodulatory and anti-inflammatory activities of CAPE. Several of the widely used anti-inflammatory agents inhibit the NF- $\kappa \mathrm{B}$ pathway, at least in part, as one of their targets. The effect of CAPE in the treatment of inflammatory diseases may be mediated through the inhibition of NF- $\mathrm{KB}$ activation, and it is believed that CAPE is a 


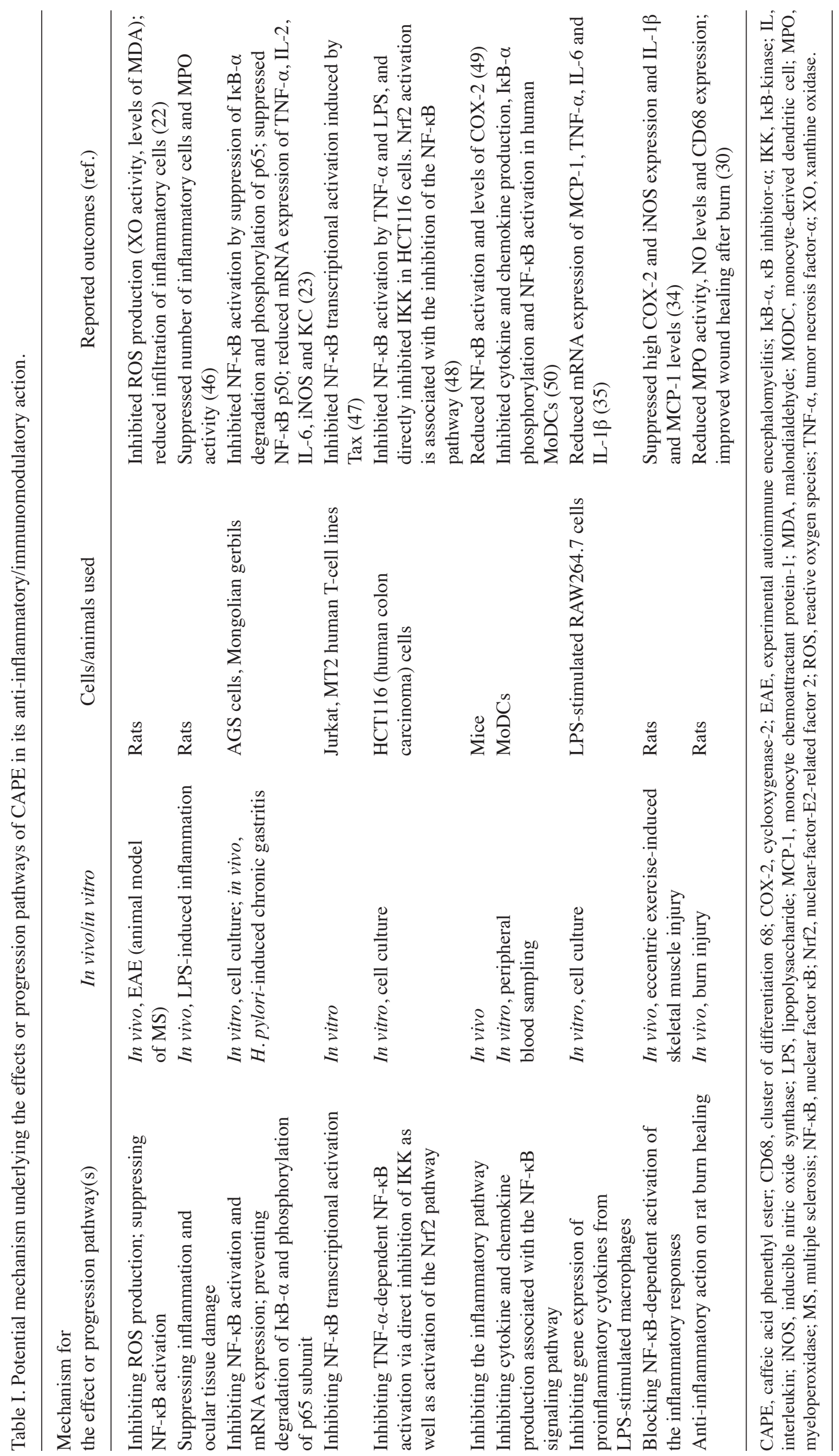


safe, natural compound and a promising drug candidate for anti-inflammation therapy.

\section{References}

1. Sud'ina GF, Mirzoeva OK, Pushkareva MA, Korshunova GA, Sumbatyan NV and Varfolomeev SD: Caffeic acid phenethyl ester as a lipoxygenase inhibitor with antioxidant properties. FEBS Lett 329: 21-24, 1993.

2. Natarajan K, Singh S, Burke TR Jr, Grunberger D and Aggarwal BB: Caffeic acid phenethyl ester is a potent and specific inhibitor of activation of nuclear transcription factor NF-kappa B. Proc Natl Acad Sci USA 93: 9090-9095, 1996.

3. Koltuksuz U, Mutuş HM, Kutlu R, Ozyurt H, Cetin S, Karaman A, Gürbüz N, Akyol O and Aydin NE: Effects of caffeic acid phenethyl ester and epidermal growth factor on the development of caustic esophageal stricture in rats. J Pediatr Surg 36: 1504-1509, 2001.

4. Akyol S, Ozturk G, Ginis Z, Armutcu F, Yigitoglu MR and Akyol O: In vivo and in vitro antineoplastic actions of caffeic acid phenethyl ester (CAPE): Therapeutic perspectives. Nutr Cancer 65: 515-526, 2013.

5. Czermak BJ, Friedl HP and Ward PA: Complement, cytokines, and adhesion molecule expression in inflammatory reactions. Proc Assoc Am Physicians 110: 306-312, 1998.

6. Ley K, Laudanna C, Cybulsky MI and Nourshargh S: Getting to the site of inflammation: The leukocyte adhesion cascade updated. Nat Rev Immunol 7: 678-689, 2007.

7. Wang X, Pang J, Maffucci JA, Pade DS, Newman RA, Kerwin SM, Bowman PD and Stavchansky S: Pharmacokinetics of caffeic acid phenethyl ester and its catechol-ring fluorinated derivative following intravenous administration to rats. Biopharm Drug Dispos 30: 221-228, 2009

8. Eming SA, Krieg T and Davidson JM: Inflammation in wound repair: Molecular and cellular mechanisms. J Invest Dermatol 127: 514-525, 2007.

9. Coussens LM and Werb Z: Inflammation and cancer. Nature 420: 860-867, 2002.

10. Leder C, Ziegler $M$ and Gawaz $M$ : Modulating immune responses and inflammation. Semin Thromb Hemost 36: 219-222, 2010.

11. Stow JL and Murray RZ: Intracellular trafficking and secretion of inflammatory cytokines. Cytokine Growth Factor Rev 24: 227-239, 2013.

12. Dinarello CA: Proinflammatory cytokines. Chest 118: 503-508, 2000.

13. Sabio G and Davis RJ: TNF and MAP kinase signalling pathways. Semin Immunol 26: 237-245, 2014.

14. Janes KA, Gaudet S, Albeck JG, Nielsen UB, Lauffenburger DA and Sorger PK: The response of human epithelial cells to TNF involves an inducible autocrine cascade. Cell 124: 1225-1239, 2006.

15. Ghosh S, May MJ and Kopp EB: NF-kappa B and Rel proteins: Evolutionarily conserved mediators of immune responses. Annu Rev Immunol 16: 225-260, 1998.

16. Chen F, Castranova V, Shi X and Demers LM: New insights into the role of nuclear factor-kappaB, a ubiquitous transcription factor in the initiation of diseases. Clin Chem 45: 7-17, 1999

17. Tak PP and Firestein GS: NF-kappaB: A key role in inflammatory diseases. J Clin Invest 107: 7-11, 2001

18. Muller DN, Dechend R, Mervaala EM, Park JK, Schmidt F, Fiebeler A, Theuer J, Breu V, Ganten D, Haller H and Luft FC: NF-kappaB inhibition ameliorates angiotensin II-induced inflammatory damage in rats. Hypertension 35: 193-201, 2000.

19. Jura J, Wegrzyn P, Korostyński M, Guzik K Oczko-Wojciechowska M, Jarzab M, Kowalska M, Piechota M, Przewlocki R and Koj A: Identification of interleukin-1 and interleukin-6-responsive genes in human monocyte-derived macrophages using microarrays. Biochim Biophys Acta 1779: 383-389, 2008.

20. Bonizzi G and Karin M: The two NF-kappaB activation pathways and their role in innate and adaptive immunity. Trends Immunol 25: 280-288, 2004.

21. Song YS, Park EH, Hur GM, Ryu YS, Lee YS, Lee JY, Kim YM and Jin C: Caffeic acid phenethyl ester inhibits nitric oxide synthase gene expression and enzyme activity. Cancer Lett 175: $53-61,2002$
22. Ilhan A, Akyol O, Gurel A, Armutcu F, Iraz M and Oztas E: Protective effects of caffeic acid phenethyl ester against experimental allergic encephalomyelitis-induced oxidative stress in rats. Free Radic Biol Med 37: 386-394, 2004.

23. Toyoda T, Tsukamoto T, Takasu S, Shi L, Hirano N, Ban H, Kumagai $\mathrm{T}$ and Tatematsu M: Anti-inflammatory effects of caffeic acid phenethyl ester (CAPE), a nuclear factor-kappaB inhibitor, on Helicobacter pylori-induced gastritis in Mongolian gerbils. Int J Cancer 125: 1786-1795, 2009.

24. Naito Y and Yoshikawa T: Molecular and cellular mechanisms involved in Helicobacter pylori-induced inflammation and oxidative stress. Free Radic Biol Med 33: 323-336, 2002.

25. Keates S, Hitti YS, Upton M and Kelly CP: Helicobacter pylori infection activates NF-kappa B in gastric epithelial cells. Gastroenterology 113: 1099-1109, 1997.

26. Aihara M, Tsuchimoto D, Takizawa H, Azuma A, Wakebe H, Ohmoto Y, Imagawa K, Kikuchi M, Mukaida N and Matsushima K: Mechanisms involved in Helicobacter pylori-induced interleukin-8 production by a gastric cancer cell line, MKN45. Infect Immun 65: 3218-3224, 1997.

27. Orban Z, Mitsiades N, Burke TR Jr, Tsokos M and Chrousos GP: Caffeic acid phenethyl ester induces leukocyte apoptosis, modulates nuclear factor-kappa B and suppresses acute inflammation. Neuroimmunomodulation 7: 99-105, 2000.

28. Hoşnuter M, Gürel A, Babucçu O, Armutcu F, Karg1 E and Işikdemir A: The effect of CAPE on lipid peroxidation and nitric oxide levels in the plasma of rats following thermal injury. Burns 30: 121-125, 2004.

29. Armutcu F, Gürel A, Hoşnuter M, Pabuçcu O and Altnyazar C: Caffeic acid phenethyl ester improves oxidative erythrocyte damage in a rat model of thermal injury. J Burn Care Rehabil 25: 171-178, 2004

30. dos Santos JS and Monte-Alto-Costa A: Caffeic acid phenethyl ester improves burn healing in rats through anti-inflammatory and antioxidant effects. J Burn Care Res 34: 682-688, 2013.

31. Khan M, Elango C, Ansari MA, Singh I and Singh AK: Caffeic acid phenethyl ester reduces neurovascular inflammation and protects rat brain following transient focal cerebral ischemia. J Neurochem 102: 365-377, 2007.

32. Jung WK, Choi I, Lee DY, et al: Caffeic acid phenethyl ester protects mice from lethal endotoxin shock and inhibits lipopolysaccharide-induced cyclooxygenase- 2 and inducible nitric oxide synthase expression in RAW 264.7 macrophages via the p38/ERK and NF-kappaB pathways. Int J Biochem Cell Biol 40: 2572-2582, 2008.

33. Lee KW, Chun KS, Lee JS, Kang KS, Surh YJ and Lee HJ: Inhibition of cyclooxygenase-2 expression and restoration of gap junction intercellular communication in H-ras-transformed rat liver epithelial cells by caffeic acid phenethyl ester. Ann NY Acad Sci 1030: 501-507, 2004.

34. Shen YC, Yen JC and Liou KT: Ameliorative effects of caffeic acid phenethyl ester on an eccentric exercise-induced skeletal muscle injury by down-regulating NF- $\mathrm{kb}$ mediated inflammation. Pharmacology 91: 219-228, 2013.

35. Juman S, Yasui N, Ikeda K, Ueda A, Sakanaka M, Negishi H and Miki T: Caffeic acid phenethyl ester suppresses the production of pro-inflammatory cytokines in hypertrophic adipocytes through lipopolysaccharide-stimulated macrophages. Biol Pharm Bull 35: 1941-1946, 2012

36. Kassim M, Mansor M, Kamalden TA, Shariffuddin II, Hasan MS, Ong G, Sekaran SD, Suhaimi A, Al-Abd N and Yusoff KM: Caffeic acid phenethyl ester (CAPE): Scavenger of peroxynitrite in vitro and in sepsis models. Shock 42: 154-160, 2014.

37. Balkwill $\mathrm{F}$ and Mantovani A: Inflammation and cancer: Back to Virchow? Lancet 357: 539-545, 2001.

38. Carrasco-Legleu CE, Márquez-Rosado L, Fattel-Fazenda S, Arce-Popoca E, Pérez-Carreón JI and Villa-Treviño S: Chemoprotective effect of caffeic acid phenethyl ester on promotion in a medium-term rat hepatocarcinogenesis assay. Int J Cancer 108: 488-492, 2004.

39. Cao Q, Kaur C, Wu CY, Lu J and Ling EA: Nuclear factor-kappa B regulates Notch signaling in production of proinflammatory cytokines and nitric oxide in murine BV-2 microglial cells. Neuroscience 192: 140-154, 2011.

40. Omene CO, Wu J and Frenkel K: Caffeic Acid Phenethyl Ester (CAPE) derived from propolis, a honeybee product, inhibits growth of breast cancer stem cells. Invest New Drugs 30: 1279-1288, 2012 
41. Coimbra M, Crielaard BJ, Storm G and Schiffelers RM: Critical factors in the development of tumor-targeted anti-inflammatory nanomedicines. J Control Release 160: 232-238, 2012.

42. Chen YJ, Shiao MS and Wang SY: The antioxidant caffeic acid phenethyl ester induces apoptosis associated with selective scavenging of hydrogen peroxide in human leukemic HL-60 cells. Anticancer Drugs 12: 143-149, 2001.

43. Watabe M, Hishikawa K, Takayanagi A, Shimizu N and Nakaki T: Caffeic acid phenethyl ester induces apoptosis by inhibition of NFkappaB and activation of Fas in human breast cancer MCF-7 cells. J Biol Chem 279: 6017-6026, 2004.

44. Lee YT, Don MJ, Hung PS, Shen YC, Lo YS, Chang KW, Chen CF and Ho LK: Cytotoxicity of phenolic acid phenethyl esters on oral cancer cells. Cancer Lett 223: 19-25, 2005.

45. Park MH, Kang DW, Jung Y, Choi KY and Min S: Caffeic acid phenethyl ester downregulates phospholipase D1 via direct binding and inhibition of $\mathrm{NF} K \mathrm{~B}$ transactivation. Biochem Biophys Res Commun 442: 1-7, 2013.

46. Yilmaz A, Yildirim O, Tamer L, et al: Effects of caffeic acid phenethyl ester on endotoxin-induced uveitis in rats. Curr Eye Res 30: 755-762, 2005.

47. Shvarzbeyn J and Huleihel M: Effect of propolis and caffeic acid phenethyl ester (CAPE) on NFKB activation by HTLV-1 Tax. Antiviral Res 90: 108-115, 2011.

48. Lee Y, Shin DH, Kim JH, et al: Caffeic acid phenethyl ester-mediated Nrf2 activation and IkappaB kinase inhibition are involved in NFkappaB inhibitory effect: Structural analysis for NFkappaB inhibition. Eur J Pharmacol 643: 21-28, 2010.

49. Bezerra RM, Veiga LF, Caetano AC, Rosalen PL, Amaral ME, Palanch AC and de Alencar SM: Caffeic acid phenethyl ester reduces the activation of the nuclear factor $\kappa \mathrm{B}$ pathway by high-fat diet-induced obesity in mice. Metabolism 61 1606-1614, 2012.

50. Wang LC, Lin YL, Liang YC, et al: The effect of caffeic acid phenethyl ester on the functions of human monocyte-derived dendritic cells. BMC Immunol 10: 39, 2009.
51. Márquez N, Sancho R, Macho A, Calzado MA, Fiebich BL and Muñoz E: Caffeic acid phenethyl ester inhibits T-cell activation by targeting both nuclear factor of activated T-cells and NF-kappaB transcription factors. J Pharmacol Exp Ther 308: 993-1001, 2004.

52. Mirzoeva OK and Calder PC: The effect of propolis and its components on eicosanoid production during the inflammatory response. Prostaglandins Leukot Essent Fatty Acids 55: 441-449, 1996.

53. Hart LA, Krishnan VL, Adcock IM, Barnes PJ and Chung KF: Activation and localization of transcription factor, nuclear factor-kappaB, in asthma. Am J Respir Crit Care Med 158: $1585-1592,1998$

54. Jung WK, Lee DY, Choi YH, Yea SS, Choi I, Park SG, Seo SK, Lee SW, Lee CM, Kim SK, et al: Caffeic acid phenethyl ester attenuates allergic airway inflammation and hyperresponsiveness in murine model of ovalbumin-induced asthma. Life Sci 82: 797-805, 2008

55. Choi IW, Kim DK, Ko HM and Lee HK: Administration of antisense phosphorothioate oligonucleotide to the p65 subunit of NF-kappaB inhibits established asthmatic reaction in mice. Int Immunopharmacol 4: 1817-1828, 2004.

56. Park JH, Lee JK, Kim HS, Chung ST, Eom JH, Kim KA, Chung SJ, Paik SY and Oh HY: Immunomodulatory effect of caffeic acid phenethyl ester in Balb/c mice. Int Immunopharmacol 4: 429-436, 2004.

57. Park SG, Lee DY, Seo SK, Lee SW, Kim SK, Jung WK, Kang MS, Choi YH, Yea SS, Choi I and Choi IW: Evaluation of anti-allergic properties of caffeic acid phenethyl ester in a murine model of systemic anaphylaxis. Toxicol Appl Pharmacol 226: 22-29, 2008.

58. Nader MA: Caffeic acid phenethyl ester attenuates IgE-induced immediate allergic reaction. Inflammopharmacology 21: 169-176, 2013.

59. Yamamoto $Y$ and Gaynor RB: Therapeutic potential of inhibition of the NF-kappaB pathway in the treatment of inflammation and cancer. J Clin Invest 107: 135-142, 2001. 